\title{
A Case of Scrub Typhus Complicated by Acute Calculous Cholecystitis

\author{
$\mathrm{Su}$ Jin Lee, Young Hye Cho ${ }^{1, *}$, Sang Yeoup Lee ${ }^{1}$, Dong Wook Jeong ${ }^{1}$, \\ Eun Jung $\mathrm{Choi}^{1}$, Yun Jin Kim², Jeong Gyu Lee ${ }^{2}$, Yu Hyun Lee ${ }^{2}$
}

Department of Internal Medicine, ${ }^{1}$ Family Medicine Clinic and Research Institute of Convergence of Biomedical Science and Technology, Pusan National University Yangsan Hospital, Yangsan; ${ }^{2}$ Department of Family Medicine, Pusan National University Hospital, Busan, Korea

We report a case of acute calculous cholecystitis through scrub typhus. A 69-year-old woman presented with a history of general myalgia, fever, and right abdominal pain. She referred to our hospital for surgical treatment of clinically suspected acute cholecystitis. Physicians concluded the cause of cholecystitis as gall bladder (GB) stone and proper antibiotics treatment of scrub typhus was started later. The patient developed acute respiratory distress syndrome and multi organ failure through scrub typhus. Five days after admission, the patient was treated with proper antibiotics and discharged on the 13th day after starting doxycycline treatment without any sequelae. In areas endemic for tsutsugamushi disease, even though a patient with GB stone presents with symptoms of acute cholecystitis, careful history and physical examination are required to reveal the existence of eschars or skin eruptions.

Keywords: Scrub Typhus; Acute Cholecystitis; Gallstones

\section{INTRODUCTION}

Scrub typhus is clinically manifested by fever, generalized lymphadenopathy, diffuse myalgia, headache, maculopapular skin rash, and eschars at the site of chigger feedings. ${ }^{1)}$ The clinical course is usually self-limited with spontaneous recovery occurring in a few days. However, severe infections may be complicated by pneumonitis, acute renal failure, acute respiratory distress syndrome (ARDS), myocarditis, and central nervous

Received: April 4, 2012, Accepted: June 26, 2012

${ }^{*}$ Corresponding Author: Young Hye Cho

Tel: 82-55-360-2018, Fax: 82-55-360-2019

E-mail: younghye82@naver.com

Korean Journal of Family Medicine

Copyright (C) 2012 The Korean Academy of Family Medicine

(ㄷ) This is an open-access article distributed under the terms of the Creative Commons Attribution Non-Commercial License (http://creativecommons.org/licenses/by-nc/3.0) which permits unrestricted noncommercial use, distribution, and reproduction in any medium, provided the original work is properly cited. system dysfunction, including delirium and confusion. ${ }^{2-7)}$ Few studies have reported the gastrointestinal manifestation of scrub typhus. ${ }^{8-11)}$ Inaba and associates have reported a case of tsutsugamushi disease complicated with cholecystitis in Japan ${ }^{12)}$; however, acute calculous cholecystitis with multiorgan failure has not been previously reported in scrub typhus. In this study, we report a case of patients with gall bladder (GB) stones who developed acute cholecystitis, ARDS, and multi organ failure after scrub typhus infection.

\section{CASE REPORT}

A healthy 69-year-old woman presented with a 3 day history of general myalgia, fever, and nausea. She resided in an urban area and had picked ginkgo nuts in the mountains 10 days before her symptoms appeared. She visited a local hospital because of right upper abdominal tenderness and was subsequently referred to our hospital for surgical treatment of clinically suspected acute 


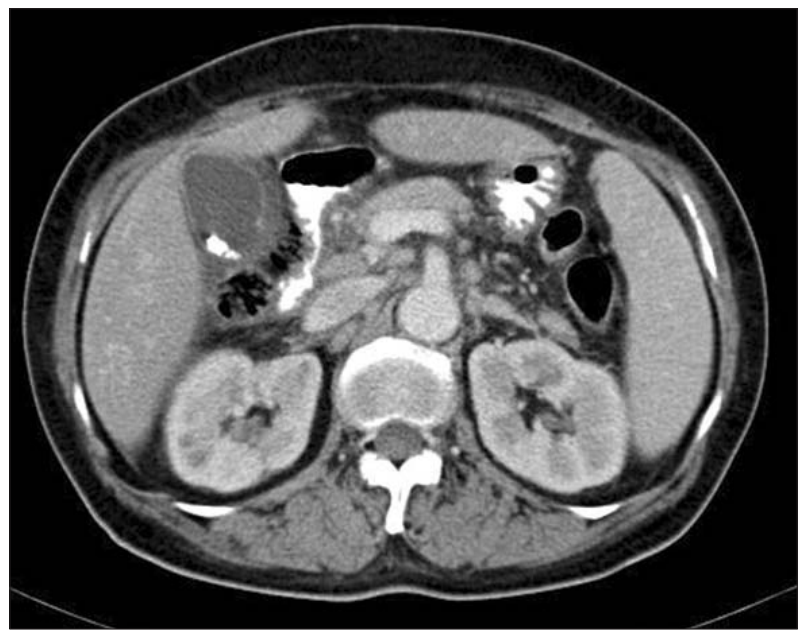

Figure 1. Abdominal computed tomography showed thickened gall bladder (GB) wall and distension of GB with GB stone.

cholecystitis. On admission, her vital signs were checked: blood pressure was 110/90 $\mathrm{mm} \mathrm{Hg}$; pulse rate, 78/min; respiratory rate, $24 / \mathrm{min}$; and body temperature, $38.5^{\circ} \mathrm{C}$. On physical examination, enlarged cervical lymph nodes and right upper abdominal tenderness with rebound tenderness was observed. No eschar was found on the trunk. According to laboratory test results, the white blood cell count was $4,510 / \mathrm{mm}^{3}$ with $70.6 \%$ segmented neutrophils; hemoglobin, $14.0 \mathrm{~g} / \mathrm{dL}$; platelet count, $57 \times 10^{3} / \mathrm{mm}^{3}$; C-reactive protein, $17.51 \mathrm{mg} / \mathrm{dL}$; aspartate aminotransferase, $374 \mathrm{IU} / \mathrm{L}$; alanine aminotransferase, 254 IU/L; alkaline phosphatase, $982 \mathrm{IU} / \mathrm{L}$; lactate dehydrogenase, 1,141 IU/L; total protein, $7.0 \mathrm{~g} / \mathrm{dL}$; albumin, $3.8 \mathrm{~g} / \mathrm{dL}$; and total bilirubin, $1.2 \mathrm{mg} / \mathrm{dL}$. Chest radiography and electrocardiogram revealed no abnormalities. Abdominal computed tomography (CT) showed edematous change in the GB wall with GB stones (Figure 1). Because acute calculous cholecystitis was suspected, intravenous ceftriaxone $(2 \mathrm{~g} / \mathrm{d})$ was initiated, and percutaneous cholecystostomy was performed. However, the patient suffered from sustained symptoms, including nausea and abdominal pain.

Four days after admission, the patient developed progressive shortness of breath, increasing sputum production, hypoxemia, and confusion, which necessitated the delivery of oxygen at $5 \mathrm{~L} / \mathrm{min}$ via nasal cannula. Arterial blood gas analysis revealed a $\mathrm{pH}$ of 7.45; $\mathrm{PaCO}_{2}, 36 \mathrm{~mm} \mathrm{Hg} ; \mathrm{PaO}_{2}, 67 \mathrm{~mm} \mathrm{Hg}$; and $\mathrm{HCO}_{3-}$, 25. Follow-up chest radiography showed extensive airspace consolidation in both lungs (Figure 2). An endotracheal intubation was performed and the patient was admitted to the intensive care unit (ICU). The next

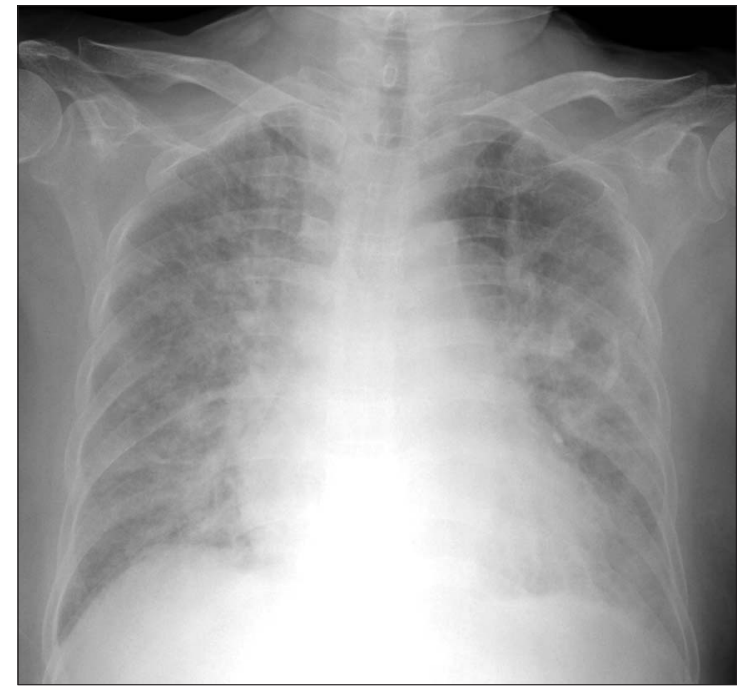

Figure 2. Chest radiography showed extensive airspace consolidation in both lungs.

day, she developed a maculopapular rash on her trunk and face. Sputum and blood cultures were negative; however, based on a suspicion of scrub typhus with acute cholecystitis and ARDS, the patient was treated with oral doxycycline $(200 \mathrm{mg} / \mathrm{d})$ and intravenous piperacillin $(4.5 \mathrm{~g} / \mathrm{d})$. Serologic test for Orientia tsutsugamushi (O. tsutsugamushi) were positive with a titer of $1: 5,120$. On the ninth day after doxycycline treatment, multiorgan function appeared to return to a normal state. The patient' s mental alertness had improved and follow-up chest radiography showed that all previous abnormalities had resolved. The patient was discharged on the thirteenth day after starting doxycycline treatment; complete blood count and biochemistry results had returned to normal range, and the patient had completely recovered. The percutaneous cholecystostomy catheter was removed at outpatient clinic after discharge, and she underwent elective cholecystectomy without complications. The number of stones was three and all were black pigment stones.

\section{DISCUSSION}

Scrub typhus is a mite-borne infectious disease caused by $O$. tsutsugamushi, intracellular microorganism. Eschars at the site of chigger feeding, lymphadenopathy, and maculopapular rash are typical signs. Fever, headache, anorexia, nausea, headache, diffuse myalgias, abdominal pain, and relative bradycardia may 
also be present. With proper medication (doxycycline) recovery is prompt and uneventful. Without proper treatment, fever generally lasts for 2 weeks. The fatality rate depends on the area, strain of rickettsia, and treatment, but is consistently higher in elderly patients. ${ }^{13)}$ Reported severe complications of scrub typhus include pneumonia, myocarditis, meningoencephalitis, acute renal failure, hepatitis, gastrointestinal bleeding, and septic shock. ${ }^{4-7,14,15)}$ A diagnosis can be made in the presence of a fourfold or greater rise in antibody titer to O. tsutsugamushi antigen by indirect immunofluorescence or Weil-Felix slide agglutination. $^{16)}$

Scrub typhus produces disseminated multi-organ vasculitis and perivasculitis of the small vessels via destruction of endothelial cells and the perivascular infiltration of leukocytes. ${ }^{17,18)}$ The mechanism responsible for the development of acute cholecystitis may be related to the vasculitis.

Inaba and associates reported tsutsugamushi disease complicated with cholecystitis, ${ }^{12)}$ but this complication is rare in the patient with solitary scrub typhus. Wang et al. ${ }^{19)}$ reported a patient with concomitant leptospirosis and scrub typhus complicated with acute acalculous cholecystitis.

Because our patient had symptoms that included fever, right upper quadrant pain, and the result of abdominal CT-revealed GB wall edema with GB stones, early treatment was focused on acute calculous cholecystitis without considering other possible options, such as scrub typhus. In our case, additional symptoms included ARDS and confusion necessitating mechanical respiration, which were processed in the ICU. Scrub typhus in elderly patients is known for its tendency for severe complications; our patients were elderly and experienced severe complications. More case studies are needed to assess the association of acute cholecystitis in patients infected with scrub typhus and pre-existing GB stones.

In our case, the patient showed relative bradycardia: an unexpectedly low heart rate response for a given increase in body temperature despite signs of infection. A study of 100 febrile patients infected with $O$. tsutsugamushi reported a prevalence of relative bradycardia of $53 \%{ }^{20)}$ The existence of pulse-temperature dissociation may help physicians identify tsutsugamushi disease in patients with acute calculous cholecystitis.

Scrub typhus can be diagnosed by assessing the patient's history of exposure, symptoms, clinical signs, and lab results, so it is important for clinicians to be cognizant of the disease. In areas endemic for tsutsugamushi disease, even though a patient with GB stone presents with symptoms of acute cholecystitis, careful history and physical examination are required to reveal the existence of eschars or skin eruptions. In addition, if a patient's heart rate is below 100 beats/min with pyrexia, the physician should be aware of the possibility of scrub typhus. Prompt treatment with doxycycline can shorten clinical illness and reduce mortality.

\section{CONFLICT OF INTEREST}

No potential conflict of interest relevant to this article was reported.

\section{ACKNOWLEDGMENTS}

This study was supported by a 2012 research grant from Pusan National University Yangsan Hospital.

\section{REFERENCES}

1. Watt G, Parola P. Scrub typhus and tropical rickettsioses. Curr Opin Infect Dis 2003;16:429-36.

2. Walker DH, Mattern WD. Rickettsial vasculitis. Am Heart J 1980;100(6 Pt 1):896-906.

3. Chien RN, Liu NJ, Lin PY, Liaw YF. Granulomatous hepatitis associated with scrub typhus. J Gastroenterol Hepatol 1995; 10:484-7.

4. Yen TH, Chang CT, Lin JL, Jiang JR, Lee KF. Scrub typhus: a frequently overlooked cause of acute renal failure. Ren Fail 2003;25:397-410.

5. Wang CC, Liu SF, Liu JW, Chung YH, Su MC, Lin MC. Acute respiratory distress syndrome in scrub typhus. Am J Trop Med Hyg 2007;76:1148-52.

6. Lee CS, Hwang JH, Lee HB, Kwon KS. Risk factors leading to fatal outcome in scrub typhus patients. Am J Trop Med Hyg 2009;81:484-8.

7. Tsay RW, Chang FY. Serious complications in scrub typhus. J Microbiol Immunol Infect 1998;31:240-4. 
8. Ito K, Awaya H, Mitchell DG, Honjo K, Fujita T, Uchisako H, et al. Gallbladder disease: appearance of associated transient increased attenuation in the liver at biphasic, contrastenhanced dynamic CT. Radiology 1997;204:723-8.

9. Chen JH, Chen WP, Huang CL, Shen WC. Dynamic helical $\mathrm{CT}$ as a novel technique for diagnosing hepatic perfusion disorders. Hepatogastroenterology 1999;46:303-7.

10. Gabata T, Kadoya M, Matsui O, Kobayashi T, Kawamori Y, Sanada J, et al. Dynamic CT of hepatic abscesses: significance of transient segmental enhancement. AJR Am J Roentgenol 2001;176:675-9.

11. Arai K, Kawai K, Kohda W, Tatsu H, Matsui O, Nakahama T. Dynamic CT of acute cholangitis: early inhomogeneous enhancement of the liver. AJR Am J Roentgenol 2003;181: 115-8.

12. Inaba H, Sugawara Y, Oouchi K, Tomichi N, Sato S, Takikawa $\mathrm{Y}$, et al. A case of Tsutsugamushi disease complicated with cholecystitis. Nihon Shokakibyo Gakkai Zasshi 2004;101:526.

13. Jensenius M, Fournier PE, Raoult D. Rickettsioses and the international traveler. Clin Infect Dis 2004;39:1493-9.

14. Aung-Thu, Supanaranond W, Phumiratanaprapin W, Phonrat B, Chinprasatsak S, Ratanajaratroj N. Gastrointestinal manifestations of septic patients with scrub typhus in
Maharat Nakhon Ratchasima Hospital. Southeast Asian J Trop Med Public Health 2004;35:845-51.

15. Kim SJ, Chung IK, Chung IS, Song DH, Park SH, Kim HS, et al. The clinical significance of upper gastrointestinal endoscopy in gastrointestinal vasculitis related to scrub typhus. Endoscopy 2000;32:950-5.

16. Blacksell SD, Bryant NJ, Paris DH, Doust JA, Sakoda Y, Day NP. Scrub typhus serologic testing with the indirect immunofluorescence method as a diagnostic gold standard: a lack of consensus leads to a lot of confusion. Clin Infect Dis 2007;44:391-401.

17. Walker TS, Mellott GE. Rickettsial stimulation of endothelial platelet-activating factor synthesis. Infect Immun 1993;61: 2024-9.

18. Silverman DJ, Bond SB. Infection of human vascular endothelial cells by Rickettsia rickettsii. J Infect Dis 1984;149: 201-6.

19. Wang NC, Ni YH, Peng MY, Chang FY. Acute acalculous cholecystitis and pancreatitis in a patient with concomitant leptospirosis and scrub typhus. J Microbiol Immunol Infect 2003;36:285-7.

20. Aronoff DM, Watt G. Prevalence of relative bradycardia in Orientia tsutsugamushi infection. Am J Trop Med Hyg 2003; 68:477-9. 